Short communication

\title{
Refuge in the sāqya: Irrigation canals as habitat for one of the world's 100 most threatened species
}

\author{
Ronaldo Sousa $^{\mathrm{a}, *}$, Amílcar Teixeira ${ }^{\mathrm{b}}$, Hassan Benaissa ${ }^{\mathrm{c}}$, Simone Varandas ${ }^{\mathrm{d}}$, Mohamed Ghamizi ${ }^{\mathrm{c}}$, \\ Manuel Lopes-Lima ${ }^{\mathrm{e}}$ \\ ${ }^{a}$ CBMA - Centre of Molecular and Environmental Biology, Department of Biology, University of Minho, Campus Gualtar, 4710-057 Braga, Portugal \\ ${ }^{\mathrm{b}}$ Centro de Investigação de Montanha (CIMO), Instituto Politécnico de Bragança, Campus de Santa Apolónia, 5300-253 Bragança, Portugal \\ ${ }^{\text {c } M u s e ́ u m ~ d ' H i s t o i r e ~ N a t u r e l l e ~ d e ~ M a r r a k e c h, ~ U n i v e r s i t e ́ ~ C a d i ~ A y y a d, ~ F a c u l t e ́ ~ d e s ~ S c i e n c e s, ~ S e m l a l i a, ~ B . P . ~} 2390$ Marrakech, Morocco \\ ${ }^{\mathrm{d}}$ CITAB-UTAD - Centre for Research and Technology of Agro-Environment and Biological Sciences, University of Trás-os-Montes and Alto Douro, Forestry Department, \\ Apartado 1013, 5001-811 Vila Real, Portugal \\ ${ }^{\mathrm{e}}$ CIBIO/InBIO - Research Center in Biodiversity and Genetic Resources, University of Porto, Campus Agrário de Vairão, Vairão, Portugal
}

\section{A R T I C L E I N F O}

\section{Keywords:}

Climate change

Condition index

Freshwater mussels

Anthropogenic ecosystems

Unionida

\begin{abstract}
A B S T R A C T
Anthropogenic habitats may function as a refuge for some species, including freshwater mussels (Bivalvia, Unionida). In this study we assessed possible differences in density, size and condition index of the Moroccan freshwater pearl mussel Pseudunio marocanus (Pallary, 1918), formerly Margaritifera marocana, colonizing anthropogenic (sāqya = irrigation canal) and natural (Bouhlou River) habitats in Morocco. Results showed that the individuals colonizing the irrigation canal located on the left bank have a significantly higher density and condition index when compared to natural conditions, but no differences were found regarding size. Since this species is listed as critically endangered by the IUCN, being also considered among the 100 most endangered organisms in the planet, the presence of $P$. marocanus in anthropogenic habitats has high conservation importance. In fact, and despite no Moroccan freshwater pearl mussels were found on the irrigation canal located in the right bank, the one located on the left bank present stable conditions for the settlement of juveniles and, if managed carefully, for the future survival of the species. However, local authorities reported frequent dredging and cleaning activities by local farmers on this sāqya without any special attention devoted to Moroccan freshwater pearl mussels (or any other species) conservation. Therefore, the results reported here can be used by scientists, managers, politicians and local people to promote future management actions that enhance the Moroccan freshwater pearl mussel protection and guarantee their future survival, including on anthropogenic habitats.
\end{abstract}

\section{Introduction}

Freshwater mussels (Bivalvia, Order Unionida) are highly threatened animals with a very unusual life cycle that include fish as hosts (Modesto et al., 2018). Threats to their survival include habitat loss and fragmentation by the construction of dams (or other infrastructures), pollution, overexploitation for shells and/or pearls, climate change including intensification of extreme events such as droughts, and introduction of non-native species affecting the mussels either directly or indirectly (e.g. through impacts on fish hosts) (Lopes-Lima et al., 2018). Although in the last two decades much more attention has been devoted to these organisms (Lopes-Lima et al., 2014), basic taxonomic and ecological information is still missing in some continents (e.g. Africa, Asia, South America), which impairs freshwater mussels' conservation
(Ferreira-Rodríguez et al., 2019). One example of a species where ecological information is clearly missing is the Moroccan freshwater pearl mussel Pseudunio marocanus (Pallary, 1918), (=Margaritifera marocana; Lopes-Lima et al., 2018). This bivalve can reach a maximum size of $17 \mathrm{~cm}$ and has an extended life cycle of probably $>50$ years (Araujo et al., 2009). Pseudunio marocanus is an endemic species of Morocco, being listed as critically endangered by the IUCN and considered one of the 100 world's most threatened species (Baillie and Butcher, 2012). This freshwater mussel has high conservation importance since it has a restricted distribution, very low abundance and phylogenetic uniqueness since it is the single recognised Margaritiferidae species in Africa (Sousa et al., 2016; Lopes-Lima et al., 2018).

In September 2016, during a survey in Bouhlou River (Figs. 1 and 2a), we found Moroccan freshwater pearl mussels in an irrigation canal

\footnotetext{
* Corresponding author.

E-mail address: rg.eco.sousa@gmail.com (R. Sousa).
} 

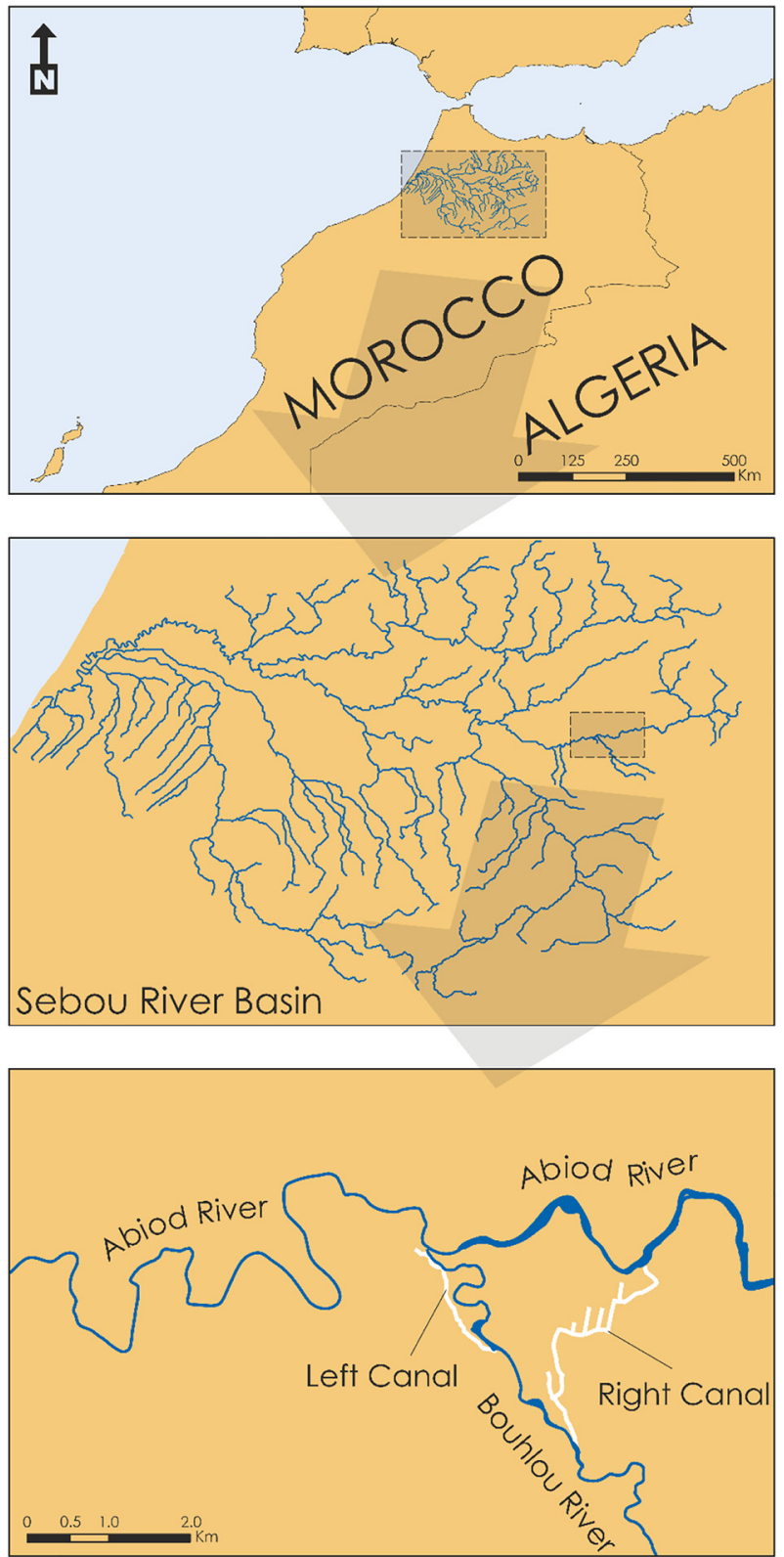

Fig. 1. Map showing the location of the irrigation canals in the downstream area of the Bouhlou River (Morocco).

with $<1 \mathrm{~m}$ width (Fig. 2b). Although earlier studies already reported the presence of freshwater mussels in anthropogenic structures (e.g. Painter, 1999; Clements et al., 2006; Gómez and Araujo, 2008; Negishi and Kayaba, 2009; Negishi et al., 2011; Nakano et al., 2017; Sousa et al., 2019), our finding was quite peculiar given the narrow width of the canal and because it was fully made of concrete, including the bottom. In addition, it was thought that $P$. marocanus had a very restricted ecological niche, colonizing only rivers with moderate to high current velocity and found preferentially in areas with coarse sediments subjected to good environmental conditions and low human disturbance (Araujo et al., 2009).

The importance of anthropogenic structures as habitat for freshwater organisms, including freshwater mussels, has been emphasized recently. Irrigation and transport canals, agricultural wetlands and ponds, rural and urban drainage ditches, rice fields, golf course lakes, aquaculture and stormwater ponds, gravel pits, wastewater treatment plants, among other man-made structures, may function as a refuge for freshwater biodiversity and be responsible for important ecosystem services (Herzon and Helenius, 2008; Brand and Snodgrass, 2010; Murray and Hamilton, 2010; Casas et al., 2011; Chester and Robson, 2013; Halliday et al., 2015; Katayama et al., 2015). In arid and semiarid areas, such as many regions in North Africa, the presence of these anthropogenic structures, mainly irrigation canals for agriculture, may favour freshwater organisms, including molluscs (Chlyeh et al., 2006). Given that the availability of surface water is a limiting resource in Mediterranean freshwater ecosystems, refuge habitats, including anthropogenic structures, may become critical components of the landscape to conserve aquatic biodiversity (Halliday et al., 2015). This situation is even more critical in arid and semiarid regions where water is under severe competition between multiple stakeholders, further exacerbated by predicted scenarios of increasing occurrence and intensity of extreme droughts and consequent reduction in streamflow and habitat availability for aquatic organisms (Beatty et al., 2017). Nevertheless, and although these anthropogenic structures mimic some of the attributes of natural ecosystems, it should be kept in mind that their potential conservation importance is a response to an increased human disturbance in a landscape that now offers much less freshwater habitat than it once did (Lundholm and Richardson, 2010; Chester and Robson, 2013).

Given the rarity of $P$. marocanus, in addition to the anthropogenic nature of the irrigation canals (locally named sāqya) in Bouhlou River, the aims of this study were to: i) assess possible differences in density, size and condition index between freshwater pearl mussels present in anthropogenic and natural habitats and ii) assess if these anthropogenic habitats function as a refuge for pearl mussels. We hypothesize that a higher density and physiological condition will be found in the natural habitat given the much simpler structure and lower heterogeneity found in anthropogenic habitats.

\section{Material and methods}

\subsection{Study area}

Since 2013, extensive surveys on all major Moroccan basins have been conducted to increase information on distribution and diversity of freshwater mussels (Froufe et al., 2016a, 2016b; Sousa et al., 2016, 2018; Gomes-dos-Santos et al., 2019). Of the $>200$ sites surveyed until 2018 just 14 contain live $P$. marocanus (restricted to the Oum Er Rbia and Sebou basins) and only Laabid (Oum Er Rbia basin) and Bouhlou (Sebou basin) Rivers still have stable populations with signs of recent recruitment (Sousa et al., 2016, 2018).

This study was conducted in the Bouhlou River (Figs. 1 and 2) which is a tributary of Abiod River and its basin is located in the Middle Atlas (for a detail description see Sousa et al., 2018). The upper catchment is protected as part of the Tazzekka National Park, which was created in 1950 and covering nowadays approximately $120 \mathrm{~km}^{2}$. The landscape includes ecologically important areas such as forests of cork and holm oaks and cedars, canyons and caves. The lower river section is unprotected and the last $4 \mathrm{~km}$ of Bouhlou River cross an extensive agriculture area with some human disturbance including water abstraction, discharge of domestic effluents and use of fertilizers and pesticides (Sousa et al., 2018).

In the lower river section an extensive irrigation infrastructure is present. This infrastructure comprises two main irrigation canals branching in smaller ditches and is nowadays managed by a local association and by the Regional Directorate of Agriculture. The construction of these canals were associated to a national project that aimed to enlarge the irrigation area $(400 \mathrm{ha})$, being the right canal constructed in 1967 and the left canal in 1992. The two main irrigation canals have approximately $10 \mathrm{~km}$ in length (around 3 and $7 \mathrm{~km}$ in the left and right bank canals, respectively), a width of approximately $1 \mathrm{~m}$, and a depth of $20 \mathrm{~cm}$ during summer conditions. Both irrigation canals were connected to the Bouhlou River by the presence of two small weirs that diverted the water from the river to the sāqya. From these two 

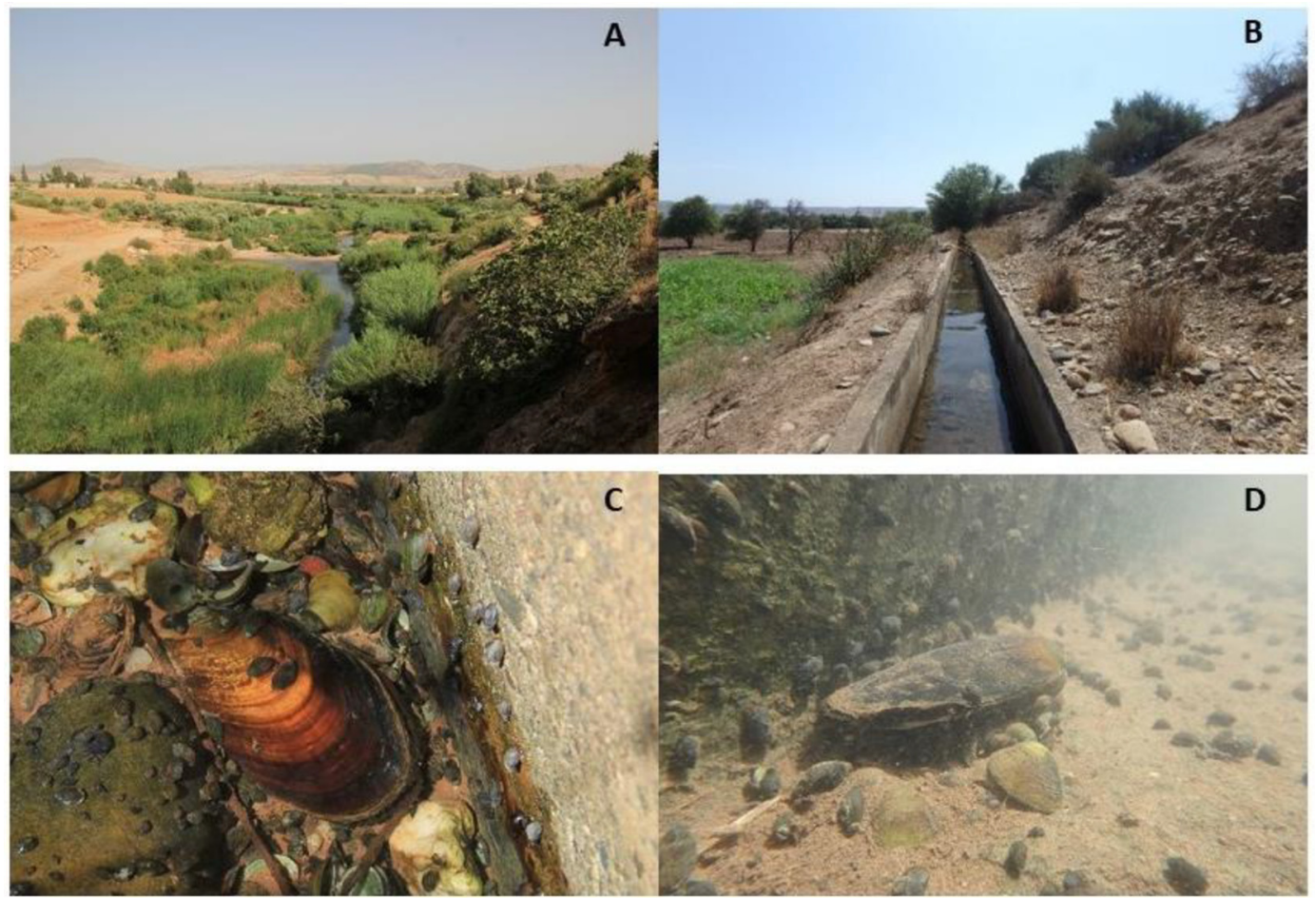

Fig. 2. A - View of the downstream area of the Bouhlou River valley (Morocco); B - Irrigation canal located in the left bank of Bouhlou River; C - Partially buried Pseudunio marocanus with a high number of gastropods and Corbicula fluminea shells; D - Unburied Pseudunio marocanus with a high number of gastropods and Corbicula fluminea shells.

main irrigation concrete canals, small ditches with a muddy bottom transport the water to the agricultural small parcels (i.e. a continuous area of land cultivated by a single farmer family) located in areas adjacent to the Bouhlou River. The main crops cultivated in the small parcels are tomatoes, onions, potatoes, watermelon, melon and carrots. It should be kept in mind that the small muddy ditches have no permanent water, being unsuitable for freshwater mussels' settlement, and therefore not surveyed in this study.

\subsection{Sampling and data analysis}

Given the rarity of $P$. marocanus and the anthropogenic nature of the habitat where some Moroccan freshwater pearl mussels were detected in 2016, detailed studies were made in August 2018 to compare the density, size and physiological condition of individuals colonizing these irrigation canals and adjacent natural habitats in Bouhlou River. For density, 60 random transects with $5 \mathrm{~m}^{2}$ (5m length and $1 \mathrm{~m}$ width) were completed: 20 transects in the irrigation canal of the left bank, 20 in the irrigation canal of the right bank and 20 in Bouhlou River (Fig. 1). Transects in the irrigation canals were made at intervals of at least $50 \mathrm{~m}$ and covering the entire length of these anthropogenic structures. Transects in the natural habitat were taken at intervals of at least $20 \mathrm{~m}$ and always located parallel (and near) to the banks (the preferred habitat and where abundance of $P$. marocanus reaches higher values in Bouhlou River; see Sousa et al., 2018). Transects in the natural habitat were performed in the last $3 \mathrm{~km}$ of the Bouhlou River, downstream the weir that diverted the water to the left canal. All pearl mussels found in the transects were counted and returned to their original position.

A random sample of 32 and 51 individuals collected in the irrigation canal of the left bank and in the adjacent Bouhlou River, respectively, were used to assess their condition index. These pearl mussels were measured (length, width and height) and their wet weight determined using a scale. The wet weight was recorded after blotting dry in paper to remove surface water in each specimen. After these measurements, all individuals were returned to their position in the irrigation canal or river. The biometric data was then used to determine the non-lethal condition index in both habitats. The condition index was calculated according to the following equation, as described in Anacleto et al. (2013).

Condition index $=\frac{[\text { Wet weight }]}{[\text { Shell length }] *[\text { Shell heigth }] *[\text { Shell width }]}$

This condition index was chosen in order to minimize possible stress to the animals.

Finally, in each of the three habitats, temperature, conductivity, dissolved oxygen and $\mathrm{pH}$ were measured (five replicates randomly taken in each habitat) using a YSI EXO 2 multi-parameter probe.

Differences in average density of Moroccan freshwater pearl mussels between anthropogenic and natural habitat were assessed by the nonparametric Kruskall-Wallis test since data depart from normality even after several transformations. Differences in average size and condition index between Moroccan freshwater pearl mussels found in the left canal and natural habitat were assessed by a $t$-test. All tests were preceded by the Shapiro-Wilk test to check if the residuals of the models had a Gaussian distribution, and the Fligner test to check for homoscedasticity (Zar, 2009). All statistical tests were performed with R.

\section{Results}

Abiotic conditions measured in the two irrigation canals and in the Bouhlou River were very similar (Table 1 ).

We found an average ( \pm sd) density of $2.5( \pm 3.2)$ ind. $5 \mathrm{~m}^{-2}$ in the left canal and $0.6( \pm 1.4)$ ind. $/ 5 \mathrm{~m}^{2}$ in Bouhlou River, but no mussels were found in the right canal (Fig. 3a). Significant differences were detected regarding the density in the left canal and the natural habitat $(\mathrm{H}=26.37 ; P<0.01)$. In the left canal most of pearl mussels were partially buried (Fig. 2c), but several individuals were found lying on their sides in an unnatural position (Fig. 2d). On the contrary, in the natural habitat all mussels were found partially buried in their normal 
Table 1

Average ( \pm sd) abiotic conditions measured in the three habitats during August 2018.

\begin{tabular}{lccc}
\hline & Left canal & Right canal & River \\
\hline Temperature $\left({ }^{\circ} \mathrm{C}\right)$ & $23.0( \pm 0.4)$ & $22.9( \pm 0.3)$ & $22.1( \pm 0.3)$ \\
Conductivity $(\mu \mathrm{S} / \mathrm{cm})$ & $526( \pm 10)$ & $527( \pm 8)$ & $530( \pm 9)$ \\
Oxygen $(\mathrm{mg} / \mathrm{l})$ & $7.1( \pm 0.4)$ & $7.1( \pm 0.3)$ & $7.2( \pm 0.3)$ \\
$\mathrm{pH}$ & $8.3( \pm 0.1)$ & $8.4( \pm 0.1)$ & $8.4( \pm 0.1)$ \\
\hline
\end{tabular}

upright position. The left canal and Bouhlou River were also colonized by other mussel species with high conservation value such as Potomida littoralis (Cuvier, 1798) and Unio foucauldianus Pallary, 1936. The invasive clam Corbicula fluminea (Müller, 1774), gastropods and fish, including Salaria sp., were also found in both irrigation canals and in Bouhlou River.

Mussel size ranged between 55 and $116.0 \mathrm{~mm}$ (average \pm $\mathrm{sd}=99.0 \pm 13.4 \mathrm{~mm}$ ) in the left canal and between 46 and $131 \mathrm{~mm}$ (average $\pm \mathrm{sd}=93.6 \pm 21.9 \mathrm{~mm}$ ) in the natural habitat (Fig. 3b). No differences were found in the average size of the pearl mussels colonizing both habitats $(t$-test $=1.26 ; P=0.21$ ).

The condition index of the mussels in the left canal is significantly higher than the ones found in the natural habitat $(t$-test $=2.91$; $\mathrm{P}<0.01)$ with an average $( \pm \mathrm{sd})$ of $6.35( \pm 0.48)$ and $5.84( \pm 0.90)$ in the left canal and Bouhlou River, respectively (Fig. 3c).

\section{Discussion}

In this study, we clearly show that irrigation canals may function as a stable habitat for one of the rarest freshwater species in the world. In fact, and contrary to our expectations, comparing Moroccan freshwater pearl mussels in the irrigation canal of the left bank with individuals subjected to natural conditions in the Bouhlou River we found that density and physiological condition were significantly higher in the anthropogenic habitat. No differences were observed regarding size.

Although it was not possible to determine when and how the Moroccan freshwater pearl mussels made their way to the left canal, we suspect that they were dispersed from the Bouhlou River by previously infested fish hosts or in alternative juveniles and/or adults were moved during floods. One way or the other, all freshwater bivalve species from the Bouhlou River (i.e. P. marocanus, U. foucauldianus, $P$. littoralis and the invasive $C$. fluminea) were also found in the left canal, and this demonstrates the potential high connectivity between both habitats. The importance of connectivity in irrigation canals have been also described for amphibians and fish (e.g. Katano et al., 2003; Wassens et al., 2008; Katayama et al., 2011). In the same vein, and given the large size of many Moroccan freshwater pearl mussels and that the left canal was functional since 1992, we also suspect that the colonization was made soon after the construction.

Density and the condition index of Moroccan freshwater pearl mussels in the left canal were higher than in the natural habitat. This situation is probably related to the similar abiotic features (including sediment characteristics in most part of its length) in both habitats. In fact, and although the irrigation canals were made of concrete, the left canal present sediment, including boulders, cobbles, gravel, and sand. Benthic species respond positively to more natural and more spatially complex substrates (Katano et al., 2003; Hamasaki et al., 2009; Gómez and Araujo, 2008; Garcia-Gonzalez and Garcia-Vazquez, 2011; Katayama et al., 2011; Sousa et al., 2019) and this was an important feature that possibly enhances the settlement and survival of $P$. marocanus. In addition, the anthropogenic habitats possibly present more stable conditions as a result of more constant water levels and current velocity along the year. Although not assessed in this study, we suspect that the natural habitat is much more influenced by typical seasonal fluctuations in river flow (i.e. very low during summer/early autumn and very high during winter, with possible occurrence of flash floods). Possibly, and given the nature of the irrigation canals, these flow fluctuations are much lower in the anthropogenic habitats and this contributes to a higher density and condition index. These stable conditions may also be responsible for a good settlement of juveniles in this canal. Freshwater mussels, including the sister species Pseudunio auricularius (=Margaritifera auricularia), are strongly dependent upon continuous water flow for food, reproduction and attraction of fish hosts (Araujo and Álvarez-Cobelas, 2016).

In the literature there is a much higher number of studies dealing with standing than running-water anthropogenic habitats. This bias may give the impression that standing-water organisms, in comparison to animals and plants of running-waters, are in advantage when colonizing anthropogenic habitats (Chester and Robson, 2013). In our study, this seems not to be the case since the left canal provides conditions for the establishment of running-water species such as $P$. marocanus. These running-water, but stable, conditions are permanently met in the Bouhlou irrigation canals, which possibly give an advantage (as reflected by their higher density and condition index) to the Moroccan freshwater pearl mussels in these anthropogenic habitats. Other environmental factors, such as higher availability of food and/or higher probability of infesting fish hosts (given the differences in water volume in both habitats), may be different in the left canal in comparison to adjacent natural conditions. The possible role of these (or other) environmental factors explaining the differences detected in both habitats remain speculative and only future studies can give a more precise answer. In addition, we do not have a definitive answer for the lack of
A

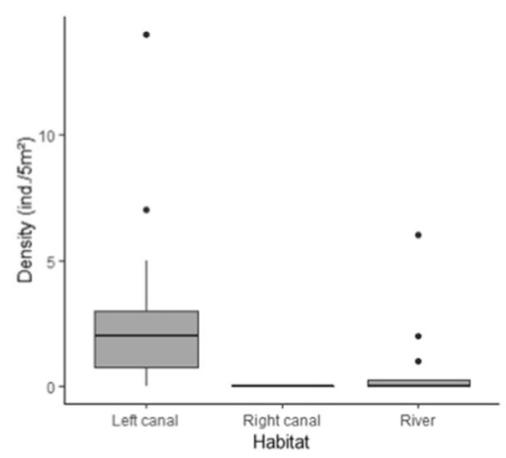

B

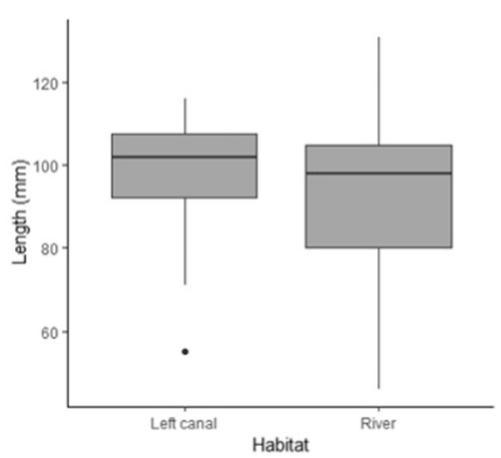

C

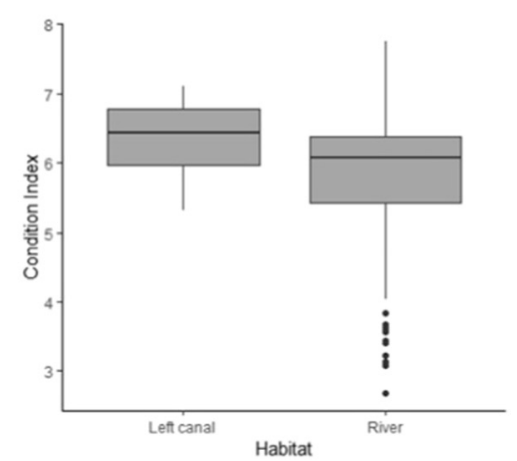

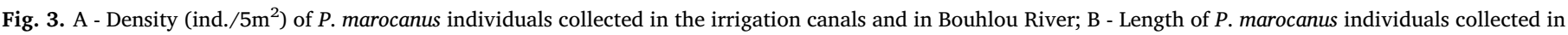

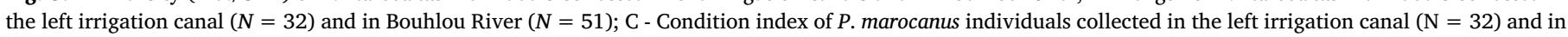

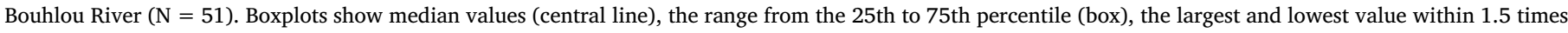
interquartile range below and above the 25th and 75th percentile (whiskers) and extreme values (dots). 
Moroccan freshwater pearl mussels (and other freshwater mussels) in the older irrigation canal located in the right bank because the physical structure of the canal is very similar and the water also comes from the Bouhlou River. However, recent dredging and clean activities (see below) in this canal may be the most plausible explanation for the lack of freshwater mussels.

In natural habitats the main threats to $P$. marocanus include habitat loss and fragmentation, water abstraction and pollution, being water shortage possibly the main factor responsible for local extirpations (Sousa et al., 2016). Therefore, and if these irrigation canals maintain the necessary quantity and quality of water they may function as refuge for $P$. marocanus (and other species) and have a high conservation value. Indeed, the importance of canals as refuge for the European giant freshwater pearl mussel have been pointed out earlier (Araujo and Ramos, 2000; Gómez and Araujo, 2008). Nevertheless, a great difference exists between these earlier examples and the one reported here. While $P$. auricularius was found in an old naturalized large canal (total length of $115 \mathrm{~km}$ with a width of $10 \mathrm{~m}$ in the most part and a depth of $3.5 \mathrm{~m}$ when it is full) with sediment (Araujo and Ramos, 2000; Gómez and Araujo, 2008), in the present case the irrigation canal was constructed recently, is very narrow and is totally made of concrete, with a $20 \mathrm{~cm}$ depth during summer conditions.

The survival of threatened species in highly disturbed areas or even in anthropogenic infrastructures is always a surprising result (Gutiérrez-Expósito et al., 2019). However, in the last years a high number of studies in freshwater ecosystems have shown that anthropogenic habitats may have high conservational importance. For example, Casas et al. (2011) clearly showed that the Iberian toothcarp Aphanius iberus have higher density, larger individual size, greater survival and reproduction in irrigation ponds (but not in irrigation canals) in comparison to natural habitats under legal protection. Although not comparing with natural ecosystems, Watson and Ormerod (2004) also showed that drainage channels (=ditches) function as suitable habitat for three freshwater gastropods in the United Kingdom: Segmentina nitida, Anisus vorticulus and Valvata macrostoma. In Maryland USA, amphibians were found to be reproducing only in anthropogenic wetlands (Brand and Snodgrass, 2010) and in southern England ditches were found to harbour uncommon species and artificial ponds supported many rare species and had high regional biodiversity compared with natural habitats (Williams et al., 2003). Many other examples, including on birds, mammals, amphibians and several species of invertebrates showed the importance of aquatic anthropogenic habitats (summarized in Chester and Robson, 2013).

Considering the role of irrigation canals conserving freshwater mussels one should also evaluate the possibility of these infrastructures function as an ecological trap (decreasing fitness or even survival due to enhanced predation or competition, transmission of diseases or parasites, and periodic dredging and/or draining) (see for example Sousa et al., 2019). Although this possibility cannot be discarded, given the great longevity of these mussels (probably $>50$ years), the higher density and condition index and the confirmed presence of juveniles, we suspect that these anthropogenic structures have stable conditions (and enough food) for P. marocanus (but see below discussion about the right canal) almost since their construction. In addition, the canals may also increase the chance of finding their fish hosts given the low volume of water and thus enhancing their recruitment.

From a conservation perspective, and given the high number of mussels found (i.e., around 1500 individuals extrapolating the average density to the overall length of the left canal), it will be important to maintain and manage these structures to retain stable water levels and sediment characteristics. Human activities (dredging and/or draining operations, among others) need to minimize any disturbance because, and according to local authorities, periodic dredging of the canals are made without any special attention devoted to freshwater mussels. In fact, in the irrigation canal located in the right bank we found no mussels and almost no sediment and this is probably a reflection of recent dredging operations. Given this background, future management measures to conserve this species in Morocco should encompass the maintenance of stable water levels and good water quality in the left canal, maintenance of the connectivity between the Bouhlou River and the irrigation canals, the sediment clearing in irrigation canals should be kept to a minimum and mitigate possible disturbance due to dredging activities. Local authorities may also use the irrigation canals as a sanctuary to protect mussels and for possible re-introduction in the natural environment. In addition, and given that the fish hosts of this mussel are still not known, it will be important to monitor the fish community to determine the host species and to confirm if mussels are reproducing and recruiting inside the canal. All these possible management measures should be always supported by participatory processes that include local farmers. Anyway, and despite the importance of irrigation canals for $P$. marocanus, the conservation of the original habitat remains a priority and a careful management of the water from the Bouhlou River for traditional farming practices is fundamental. In fact, the conservation importance of these irrigation canals (or other anthropogenic structures) for freshwater mussels, including $P$. marocanus, increases as a result of growing disturbance in natural habitats.

\section{Conclusion}

Currently, the scientific community is focused on how humans have been degrading freshwater ecosystems and much less attention has been devoted to how anthropogenic infrastructures may benefit biodiversity (Martínez-Abraín and Jímenez, 2015). Although the present study is geographically restricted, we recommend that future worldwide surveys and management actions devoted to freshwater mussel conservation have to include anthropogenic structures such as irrigation canals. These artificial habitats cannot substitute natural conditions, but in a context of global change their maintenance may act as an insurance to protect some species from local extinction. Future climate scenarios predict an increase in number and intensity of extreme climatic events such as droughts in the Mediterranean region (Sousa et al., 2016) and so, the identification of refuge habitats, as described here, may be critical for the protection of freshwater biodiversity. According to Chester and Robson (2013) the largest limitation to anthropogenic habitats providing refuges for freshwater biodiversity is the lack of recognition of their conservational value. These habitats are usually ignored as part of water management policy and this could lead to their omission as part of the water management (Gómez and Araujo, 2008; Canals et al., 2011; Casas et al., 2011; Chester and Robson, 2013). In fact, environmentally friendly management strategies to preserve biodiversity in irrigation systems are non-existent in Morocco, but they are urgently needed, particularly in systems such as the one presented in this study with a high value for the conservation of threatened species. There are hundreds of thousands of kilometres of irrigation canals (and similar structures) worldwide and these habitats may be important for sustaining highly imperilled species such as $P$. marocanus. If managed carefully, the irrigation canals in the Bouhlou River will constitute a valuable refuge and will function as an insurance to the possible extinction of one of the world's 100 most threatened species in the planet.

\section{Acknowledgments}

This study was conducted within the scope of project «Biodiversity and conservation of the critically endangered freshwater mussels in Morocco: ecogeographic, genetic and physiological information", funded by Mohamed bin Zayed Species Conservation Fund (Reference 15256799) and project «Breeding the most endangered bivalve on Earth: Margaritifera marocana», funded by IUCN SOS save our species fund (Reference 2015B-015). MLL was supported by the Portuguese Foundation for Science and Technology (FCT) grant number SFRH/BD/ 115728/2016. We acknowledge Joana Garrido Nogueira for the help preparing the Figures. We also acknowledge the editor Dr. Amanda 
Bates and three anonymous referees for the helpful suggestions.

\section{References}

Anacleto, P., Maulvault, A.L., Barrento, S., Mendes, R., Nunes, M.L., Rosa, R., Marques, A., 2013. Physiological responses to depuration and transport of native and exotic clams at different temperatures. Aquaculture 408-409, 136-146.

Araujo, R., Álvarez-Cobelas, M., 2016. Influence of flow diversions on giant freshwater pearl mussel populations in the Ebro River, Spain. Aquat. Conserv. 26, 1145-1154.

Araujo, R., Ramos, M.A., 2000. Status and conservation of the relict giant European freshwater pearl mussel Margaritifera auricularia (Spengler, 1793). Biol. Conserv. 96, 233-239.

Araujo, R., Toledo, C., Van Damme, D., Ghamizi, M., Machordom, A., 2009. Margaritifera marocana (Pallary, 1918): a valid species inhabiting Moroccan rivers. J. Molluscan Stud. 75, 95-101.

Baillie, J.E.M., Butcher, E.R., 2012. Priceless or Worthless? The World's Most Threatened Species. Zoological Society of London, London.

Beatty, S., Alan, M., Lymbery, A., Jordan, M.S., Morgan, D., Impson, D., Marr, S., Ebner, B., Weyl, O.L.F., 2017. Rethinking refuges: implications of climate change for dam busting. Biol. Conserv. 209, 188-195.

Brand, A.B., Snodgrass, J.W., 2010. Value of artificial habitats for amphibian reproduction in altered landscapes. Conserv. Biol. 24, 295-301.

Canals, R.M., Ferrer, V., Iriarte, A., Carcamo, S., Emeterio, L.S., Villanueva, E., 2011. Emerging conflicts for the environmental use of water in high-valuable rangelands. Can livestock water ponds be managed as artificial wetlands for amphibians? Ecol. Eng. 37, 1443-1452.

Casas, J.J., Sánchez-Oliver, J.S., Sanz, A., Furné, M., Trenzado, C., Juan, M., Paracuellos, M., Suárez, M.D., Fuentes, F., Gallego, I., Gil, C., Ramos-Miras, J.J., 2011. The paradox of the conservation of an endangered fish species in a Mediterranean region under agricultural intensification. Biol. Conserv. 144, 253-262.

Chester, E.T., Robson, B.J., 2013. Anthropogenic refuges for freshwater biodiversity: their ecological characteristics and management. Biol. Conserv. 166, 64-75.

Chlyeh, G., Dodet, M., Delay, B., Khallaayoune, K., Jarne, P., 2006. Spatio-temporal distribution of freshwater snail species in relation to migration and environmental factors in an irrigated area from Morocco. Hydrobiologia 553, 129-142.

Clements, R., Koh, L.P., Lee, T.M., Meier, R., Li, D., 2006. Importance of reservoirs for the conservation of freshwater molluscs in a tropical urban landscape. Biol. Conserv. 128, $136-146$.

Ferreira-Rodríguez, N., Akiyama, B.Y., Aksenova, O., Araujo, R., Barnhart, C., Bespalaya, Y., Bogan, A., Bolotov, I.N., Budha, P.B., Clavijo, C., Clearwater, S.J., Darrigran, G., Do, V.T., Douda, K., Froufe, E., Graf, D., Gumpinger, C., Humphrey, C.L., Johnson, N.A., Klishko, O., Klunzinger, M.W., Kovitvadhi, S., Kovitvadhi, U., Lajtner, J., Lennart, H., Lopes-Lima, M., Moorkens, E.A., Nagayama, S., Nagel, K.-O., Nakano, M., Negishi, J., Ondina, P., Oulasvirta, P., Pfeiffer, P., Prié, V., Riccardi, N., Rudzīte, M., Seddon, M., Sheldon, F., Sousa, R., Strayer, D.L., Takeuchi, M., Taskinen, J., Teixeira, A., Tiemann, J., Urbańska, M., Varandas, S., Vinarski, M., Wicklow, B.J., Zając, T. Vaughn, C.C., 2019. Research priorities for freshwater mussel conservation assessment. Biol. Conserv. 231, 77-87.

Froufe, E., Gonçalves, D.V., Teixeira, A., Sousa, R., Varandas, S., Ghamizi, M., Zieritz, A., Lopes-Lima, M., 2016a. Who lives where? Molecular and morphometric analyses clarify which Unio species (Unionida, Mollusca) inhabit the southwestern Palearctic. Org. Divers. Evol. 16, 597-611.

Froufe, E., Prié, V., Faria, J., Ghamizi, M., Gonçalves, D., Gürlek, M.E., Karaouzas, I., Kebapçi, Ü., Şereflişan, H., Sobral, C., Sousa, R., Teixeira, A., Varandas, S., Zogaris, S., Lopes-Lima, M., 2016b. Phylogeny, phylogeography, and evolution in the Mediterranean region: news from a freshwater mussel (Potomida, Unionida). Mol. Phylogenet. Evol. 100, 322-332.

Garcia-Gonzalez, C., Garcia-Vazquez, E., 2011. The value of traditional troughs as freshwater shelters for amphibian diversity. Aquat. Conserv. Mar. Freshwat. Ecosyst. 21, 74-81.

Gomes-dos-Santos, A., Froufe, E., Gonçalves, D.V., Sousa, R., Prié, V., Ghamizi, M., Benaissa, H., Varandas, S., Teixeira, A., Lopes-Lima, M., 2019. Freshwater conservation assessments in (semi)arid regions: testing river intermittence and buffer strategies using freshwater mussels (Bivalvia, Unionida) in Morocco. Biol. Conserv. 236, 420-434.

Gómez, I., Araujo, R., 2008. Channels and ditches as the last shelter for freshwater mussels: the case of Margaritifera auricularia and other naiads inhabiting the mid Ebro
River Basin, Spain. Aquat. Conserv. 18, 658-670.

Gutiérrez-Expósito, C., García-Gorria, R., Qninba, A., Clavero, M., Revilla, E., 2019. The farmland refuge of the last Andalusian Buttonquail population. In: Global Ecology and Conservation, pp. e00590.

Halliday, B.T., Matthews, Ty.G., Iervasi, D., Dodemaide, D.T., Pickett, P.J., Linn, M.M., Burns, A., Bail, I., Lester, R.E., 2015. Potential for water-resource infrastructure to act as refuge habitat. Ecol. Eng. 84, 136-148.

Hamasaki, K., Yamanaka, T., Tanaka, K., Nakatani, Y., Iwasaki, N., Sprague, D.S., 2009. Relative importance of within-habitat environment, land use and spatial autocorrelations for determining odonate assemblages in rural reservoir ponds in Japan. Ecol. Res. 24, 597-605.

Herzon, I., Helenius, J., 2008. Agricultural drainage ditches, their biological importance and functioning. Biol. Conserv. 141, 1171-1183.

Katano, O., Hosoya, K., Iguchi, K., Yamaguchi, M., Aonuma, Y., Kitano, S., 2003. Species diversity and abundance of freshwater fishes in irrigation ditches around rice fields. Environ. Biol. Fish 66, 107-121.

Katayama, N., Saitoh, S., Amano, T., Miyashita, T., 2011. Effects of modern drainage systems on the spatial distribution of loach in rice ecosystems. Aquat. Conserv. Mar. Freshwat. Ecosyst. 21, 146-154.

Katayama, N., Baba, Y.G., Kusumoto, Y., Tanaka, K., 2015. A review of post-war changes in rice farming and biodiversity in Japan. Agric. Syst. 132, 73-84.

Lopes-Lima, M., Teixeira, A., Froufe, E., Lopes, A., Varandas, S., Sousa, R., 2014. Biology and conservation of freshwater bivalves: past, present and future perspectives. Hydrobiologia 735, 1-13.

Lopes-Lima, M., Bolotov, I., Do, V.T., Aldridge, D., Fonseca, M., Gan, M.H., Gofarov, M.Y., Kondakov, A., Prié, V., Sousa, R., Varandas, S., Vikhrev, I., Teixeira, A., Wu, R.W., Wu, X., Zieritz, A., Froufe, E., Bogan, A., 2018. An expansion and systematics redefinition of the most threatened freshwater mussel family, the Margatiferidae. Mol. Phylogenet. Evol. 127, 98-118.

Lundholm, J.T., Richardson, P.J., 2010. Habitat analogues for reconciliation ecology in urban and industrial environments. J. Appl. Ecol. 47, 966-975.

Martínez-Abraín, A., Jímenez, J., 2015. Anthropogenic areas as incidental substitutes for original habitat. Conserv. Biol. 30, 593-598.

Modesto, V., Ilarri, M., Souza, A.T., Lopes-Lima, M., Douda, K., Clavero, M., Sousa, R. 2018. Fish and mussels: importance of fish for freshwater mussel conservation. Fish Fish. 19, 244-259.

Murray, C.G., Hamilton, A.J., 2010. Perspectives on wastewater treatment wetlands and waterbird conservation. J. Appl. Ecol. 47, 976-985.

Nakano, M., Takakura, K.-I., Morii, K., Urabe, M., 2017. Unionid mussel composition and ditch environments in floodplain and alluvial fan geomorphic types: a case study of a Lake Biwa river basin. Limnology 18, 41-49.

Negishi, J.N., Kayaba, Y., 2009. Effects of handling and density on the growth of the unionid Mussel (Pronodularia japanensis). J. N. Am. Benthol. Soc. 28, 821-831.

Negishi, J.N., Doi, H., Katano, I., Kayaba, Y., 2011. Seasonally tracking vertical and horizontal distribution of unionid mussels (Pronodularia japanensis): implications for agricultural drainage management. Aquat. Conserv. 21, 49-56.

Painter, D., 1999. Macroinvertebrate distributions and the conservation value of aquatic Coleoptera, Mollusca and Odonata in the ditches of traditionally managed and grazing fen at Wicken Fen, UK. J. Appl. Ecol. 36, 33-48.

Sousa, R., Varandas, S., Teixeira, A., Ghamizi, M., Froufe, E., Lopes-Lima, M., 2016. Pearl mussels (Margaritifera marocana) in Morocco: conservation status of the rarest bivalve in African fresh waters. Sci. Total Environ. 547, 405-412.

Sousa, R., Teixeira, A., Santos, A., Benaissa, H., Varandas, S., Ghamizi, M., Prié, V., Froufe, E., Lopes-Lima, M., 2018. Oued Bouhlou: a new hope for the Moroccan pearl mussel. Aquat. Conserv. 28, 247-251.

Sousa, R., Nogueira, J.G., Lopes-Lima, M., Varandas, S., Teixeira, A., 2019. Water mill canals as habitat for Margaritifera margaritifera: stable refuge or an ecological trap? Ecol. Indic. 106, 105469.

Wassens, S., Watts, R.J., Jansen, A., Roshier, D., 2008. Movement patterns of southern bell frogs (Litoria raniformis) in response to flooding. Wildl. Res. 35, 50-58.

Watson, A.M., Ormerod, S.J., 2004. The distribution of three uncommon freshwater gastropods in the drainage ditches of British grazing marshes. Biol. Conserv. 118, 455-466.

Williams, P., Whitfield, M., Biggs, J., Bray, S., Fox, G., Nicolet, P., Sear, D., 2003. Comparative biodiversity of rivers, streams, ditches and ponds in an agricultural landscape in Southern England. Biol. Conserv. 115, 329-341.

Zar, J.H., 2009. Biostatistical Analysis, 5th ed. Prentice-Hall, Englewood Cliffs. 